\title{
Assembly of Tobacco Mosaic Virus In Vitro: Effect of State of Polymerization of the Protein Component
}

\author{
(quantitative electron microscopy/RNA-protein interactions)
}

\author{
KENNETH E. RICHARDS AND ROBLEY C. WILLIAMS
}

The Virus Laboratory and Department of Molecular Biology, University of California, Berkeley, Calif. 94720

Contributed by Robley C. Williams, February 22, 1972

\begin{abstract}
The in vitro assembly of tobacco mosaic virus from its constituent RNA and protein was followed by methods of electron microscopy. The effect of the state of polymerization of the protein upon the initiation of assembly of tobacco mosaic virus rods, and the subsequent rod elongation, was investigated. Protein in two identifiable states of polymerization was used: the $20 S$ "disc", consisting of 34 monomers arrayed as a two-ring structure, and the 4S "A-protein", consisting of polymers in the trimer range of size. It is concluded, in confirmation of results of others, that rod assembly is initiated by the attachment of one end of the RNA chain of tobacco mosaic virus to one (or possibly a few) disc structure. Rod elongation, on the other hand, is found to take place by the sequential addition of structures of the size of A-protein, or smaller, to the previously initiated rods.
\end{abstract}

It has recently been shown (1) that the in vitro assembly of tobacco mosaic virus (TMV) from its protein and RNA components is affected by the state of polymerization of the protein that is added to the RNA in the reaction mixture. Two identifiable states of the protein are easily recognized in the ultracentrifuge: a $20 \mathrm{~S}$ polymer believed to contain 34 monomeric units of tobacco mosaic virus protein (2), and material giving rise to a reaction boundary sedimenting at about $4 \mathrm{~S}$ and consisting of a mixture of low states of aggregation, with trimer predominating. The $20 \mathrm{~S}$ component has been shown to exist as a relatively stable, two-ring disc with the rings apposed in polar fashion (3). Under near-physiological conditions, and at a concentration of $5 \mathrm{mg} / \mathrm{ml}$, the equilibrium proportions of the $20 \mathrm{~S}$ and $4 \mathrm{~S}$ material are about $70: 30$. If the solution temperature is lowered to $5^{\circ}$, the $4 \mathrm{~S}$ component is notably prominent and no $20 \mathrm{~S}$ material can be detected. Upon rewarming to $20^{\circ}$, the former equilibrium proportions are established after several hours. Since the $20 \mathrm{~S}$ discs are the major species, this material is here referred to as "disc protein." The material sedimenting at $4 \mathrm{~S}$ is generally called "A-protein."

When disc protein is added to TMV-RNA in stoichiometric proportions (20:1) and turbidity is followed as a measure of rod assembly, turbidity increases much more rapidly than it does when the same amount of A-protein alone is added. Disc protein added to the reaction mixture with A-protein; in amounts considerably greater than catalytic, will cause the turbidity, once again, to rise rapidly. It has been concluded from this and other types of observations that the assembly of TMV rods proceeds by stepwise addition of the

Abbreviation: TMV, tobacco mosaic virus. two-ring structures present in the disc protein, each planar disc altering its configuration slightly upon incorporation to provide the helical continuity found in the assembled rod (1). We are not convinced that these observations necessarily lead to the proposed model for in vitro assembly of TMV. On the face of it, the model seems improbable because of its implicit topological complexity. The TMV helical rod is known to have one turn of the RNA chain for every turn of attached protein monomers; the assembly of such a structure would be remarkably difficult if the structural units of incorporation are two-ring discs (1).

We have made additional investigations of the role of the two-ring discs and the A-protein in the assembly of TMV rods, using methods of quantitative electron microscopy (4) to follow the initiation and elongation of the rods in the reaction mixture. Our results confirm the finding (1) that discs are used as nuclei for the initiation of rod assembly, but they are incompatible with the concomitant conclusion that the discs are also the units of protein incorporated into elongating rods.*

\section{MATERIALS AND METHODS}

TMV-RNA was prepared by the method of Fraenkel-Conrat (5). TMV-protein was prepared, with minor modifications, by the alkali-column method of Durham (6): a water solution of TMV $(30-40 \mathrm{mg} / \mathrm{ml})$ was dialyzed overnight against a large volume of $0.1 \mathrm{M}$ ethanolamine $-5 \mathrm{mM} \mathrm{HCl}(\mathrm{pH} 11.0)$ at $4^{\circ}$, then dialyzed several hours against $17 \mathrm{mM}$ Tris $-0.01 \mathrm{M}$ $\mathrm{HCl}$ (pH 8.0). Undegraded material was removed by $70 \mathrm{~min}$ of centrifugation at $105,000 \times g$. A small DEAE-cellulose column was prepared (1-ml bed volume/50 mg of virus) and equilibrated with the Tris $\cdot \mathrm{HCl}$ buffer. The supernatant from the centrifugation was passed through the column, which selectively binds the RNA. The eluted protein had a $282 / 250 \mathrm{~nm}$ absorbance ratio of $2.5: 2.7$. It was then converted to stable, helical-rod form by dialysis against sodium acetate buffer ( $\mathrm{pH} 5)$ and stored at $4^{\circ}$. For use in reaction mixtures, samples of stored material, at a concentration of $5 \mathrm{mg} / \mathrm{ml}$ (based upon $A_{282}=1.27$, per $1 \mathrm{mg} / \mathrm{ml}$ ), were dialyzed against $41 \mathrm{mM}$ (0.1 ionic strength) sodium phosphate

* During the preparation of this manuscript, a paper has appeared (7) on the effect of different aggregative states of TMVprotein on the in vitro assembly of TMV rods. The roles of the discs and of the A-protein subunits in the assembly process as reported there are substantially in agreement with our results. 


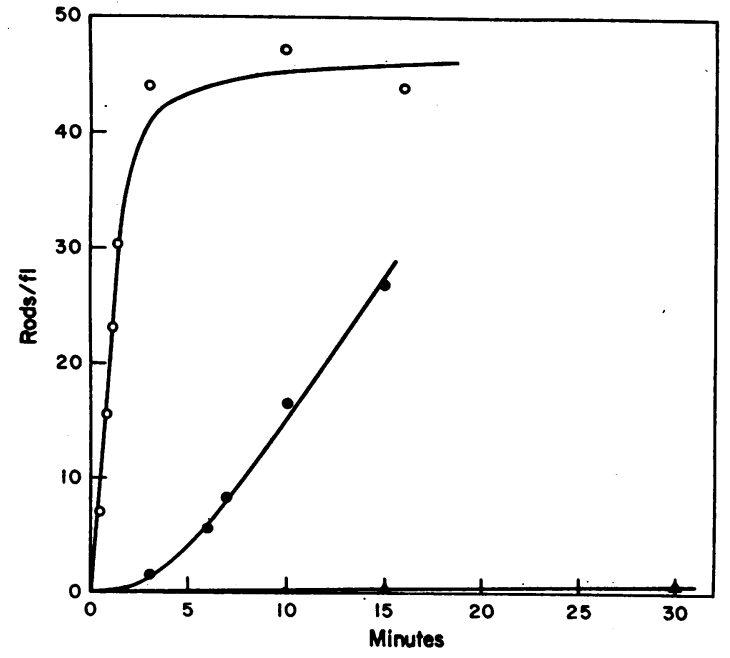

Fig. 1. TMV rod formation. Reaction mixture and preparation for electron microscopy throughout are as in Methods. Reactions were in sodium phosphate buffer. $(O)$ Disc protein reacted at $20^{\circ}$; A-protein reacted at $(\bullet) 20^{\circ},(\Delta) 15^{\circ},(\Delta) 10^{\circ}$. fl, femtoliter $=10^{-15}$ liter.

buffer at $4^{\circ}$ and $\mathrm{pH} 7$. After dialysis the material was allowed to equilibrate in the same buffer for $10-15 \mathrm{hr}$ at $20^{\circ}$. Ultracentrifuge patterns showed $60-70 \%$ of the material (disc protein) sedimenting at $20 \mathrm{~S}$, and the remainder of the material sedimenting at about $4 \mathrm{~S}$. As occasion required, samples were chilled to $0^{\circ}$ for periods of $15 \mathrm{~min}$ or longer; centrifugal analysis (at $4-8^{\circ}$ ) showed a single, $4 \mathrm{~S}$ peak for this material (A-protein). It should be noted that, in any one reaction, both the disc protein and the A-protein had the same preparative history, except for the brief chilling of the A-protein.

Reaction Mixtures for rod assembly were: (a) $10 \mu \mathrm{l}$ of TMVRNA ( $5 \mathrm{mg} / \mathrm{ml}$ ) was added to $0.4 \mathrm{ml}$ of TMV protein (5 $\mathrm{mg} / \mathrm{ml}$ ) in $41 \mathrm{mM}$ sodium phosphate buffer $(\mathrm{pH} 7)$ at $20^{\circ}$, to which $5 \mu$ l of bentonite $(2.5 \mathrm{mg} / \mathrm{ml})$ had been added; (b) 10 $\mu l$ of TMV-RNA $(5 \mathrm{mg} / \mathrm{ml})$ and $0.2 \mathrm{ml}$ of TMV protein $(5 \mathrm{mg} / \mathrm{ml}$ ) (both in $41 \mathrm{mM}$ sodium phosphate buffer) were added to $0.8 \mathrm{ml}$ of $0.1 \mathrm{M}$ sodium pyrophosphate buffer ( $\mathrm{pH}$ 7.3) at $26^{\circ}$, with addition of bentonite as before.

Samples for electron microscopy were taken from the reaction mixture at intervals of 2-3 min and diluted 200-fold (reaction mixture $a$ ) or 50-fold (reaction mixture $b$ ) in $2 \mathrm{mM}$ ice-cold $\mathrm{NH}_{4} \mathrm{HCO}_{3}$ (pH 7.8) containing polystyrene latex spheres, 90 -nm diameter, at a density of $1.2 \times 10^{11}$ particles/ ml. [Separate experiments showed that such dilution had no discernible effect on native TMV, but that it depolymerized RNA-free protein discs and larger aggregates to material not detectable in the electron microscope. It was, therefore, assumed that any visible material (rods of measurable length and disc-like structures) represents only the TMV protein that is bound to RNA as it is in the native virus.] After 5 min in the dilution medium, the sample was sprayed from a lowvelocity nebulizer upon electron microscope grids with collodion films; samples were then shadowed (by rotary shadowing) with uranium. Micrographs of whole drop patterns were obtained from which the number of visible rods per $\mathrm{ml}$ of reaction mixture could be counted; the length of each rod was measured to an estimated accuracy of about 5 $\mathrm{nm}$. Short rods seen on end ("doughnuts") were arbitrarily assigned a length of $7.5 \mathrm{~nm}$. When the reaction was performed in $0.1 \mathrm{M}$ pyrophosphate buffer, the diluted sample was dialyzed in the cold against $2 \mathrm{mM} \mathrm{NH}_{4} \mathrm{HCO}_{3}(\mathrm{pH} \mathrm{7.8)}$ for the removal of most of the nonvolatile salts. About 200 rods were measured in a given sample; a standard deviation estimated to be $\pm 2.5 \mathrm{~nm}$ was obtained for the average rod length. Rods of greatly differing lengths were seen in those samples that had undergone extended reaction times, indicating that the RNA preparation was not monodisperse.

\section{RESULTS AND DISCUSSION}

TMV rod formation in sodium phosphate bufferconstant temperature during reaction

The time course of formation of rods, without regard to their lengths, is shown in Fig. 1, where the temperatures at which the protein component was added to the reaction were: disc protein alone at $20^{\circ}$ and A-protein rapidly adjusted from 0 to 20,15 , and $10^{\circ}$. It is seen that when disc protein was used, the number of rods formed increased within about $3 \mathrm{~min}$ to a major fraction of those that eventuálly formed during a prolonged reaction interval, whereas reaction with A-protein alone at $20^{\circ}$ resulted in much more gradual rod formation. Reaction with A-protein at 15 and $10^{\circ}$ produced practically no rods during $30 \mathrm{~min}$. The behavior of rod formation shown in Fig. 1 is compatible with the notion (1) that only the discs, or aggregates distinctly larger than the $4 \mathrm{~S}$ material, readily participate in the initiation of the assembly of TMV rods. The very small increase in initiation of rod formation when A-protein was the sole protein added is presumably a consequence of its gradual polymerization to discs, at $20^{\circ}$, with subsequent nucleation of rod assembly. It was found by ultracentrifuge examination that the A-protein, at 10 and $15^{\circ}$, is not detectably polymerized into $20 \mathrm{~S}$ protein over a period of $60 \mathrm{~min}$; it is, therefore, not surprising that no rods are formed at these lower temperatures.

\section{TMV rod formation in sodium phosphate buffer-} temperature change during reaction

When discs are abundant, the initiation of rod assembly is essentially completed within $3 \mathrm{~min}$ (Fig. 1), but rod elongation is far from complete. A method was devised for measurement of the rate of elongation of previously initiated rods when the protein available for incorporation was in a form substantially smaller than the $20 \mathrm{~S}$ discs, mainly A-protein. A reaction

TABLE 1. Elongation at different temperatures of previously initiated $T M V$ rods

\begin{tabular}{lccc}
\hline & \multicolumn{3}{c}{$\begin{array}{c}\text { Average rod length (nm) } \\
\text { at intervals after } \\
\text { temperature change }\end{array}$} \\
\cline { 2 - 4 } $\begin{array}{c}\text { Temperature } \\
\text { change }\end{array}$ & 0 min & 9 min & 25 min \\
\hline (1) $0-10^{\circ}$ & 32 & 36 & 40 \\
(2) $0-15^{\circ}$ & 32 & 42 & 52 \\
(3) $20-20^{\circ}$ (control) & 32 & 45 & 60 \\
\hline
\end{tabular}

Composition of reaction mixture and preparation for electron microscopy as in Methods. Disc protein was previously reacted with RNA for 4 min at $20^{\circ}$. Rows (1) and (2): reaction mixture was then chilled to $0^{\circ}$ for $15 \mathrm{~min}$, warmed again to (1) $10^{\circ}$ and (2) $15^{\circ}$, and was sampled after intervals shown. Row (3): control samples with reaction continuing at $20^{\circ}$. 
mixture containing RNA and disc protein was rapidly chilled to $0^{\circ}$ after incubation for $3 \mathrm{~min}$ at $20^{\circ}$, thereby stopping further rod elongation and converting all the protein not RNA-bound to A-protein. After $15 \mathrm{~min}$ at $0^{\circ}$ the samples were warmed again to 10 and $15^{\circ}$ to allow further rod assembly (if any) to proceed. For comparison, a sample of the initial reaction mixture with disc-protein was maintained at $20^{\circ}$. The results are shown in Table 1 , where it is apparent that rod elongation does take place at 10 and at $15^{\circ}$, although more slowly than at $20^{\circ}$. It is to be recalled (Fig. 1) that when A-protein alone is in the TMV protein-RNA reaction mixture, held at 10 and $15^{\circ}$ for $25 \mathrm{~min}$, a very small number of rods of any length are formed (presumably owing to the absence of discs for initiation). We conclude that the rod elongation shown in Table 1 is not due to the addition of disc units (20S) to previously initiated rods, but must be due to the incorporation of protein aggregates of smaller size.

In a second set of experiments, the temperature was dropped as before, but the temperature of the RNA-protein mixture was raised to $20^{\circ}$ after 15 min at $0^{\circ}$. For comparison, a sample of the initial reaction mixture was maintained at $20^{\circ}$, and a sample was also prepared in which A-protein alone was added to the RNA at $20^{\circ}$ and the mixture was maintained at that temperature. The results (Fig. 2) show that the amount of protein converted to rods, by addition of protein to previously initiated rods, is as great when A-protein alone is the protein supply as it is when the disc protein is the supply throughout (Curve A). The A-protein control (Curve B) shows that in the absence of previously initiated rods some conversion of protein to rods took place during the 15-min reaction. A possible mechanism for this conversion would be one in which there was initial polymerization of the A-protein to discs, followed by incorporation of these discs into growing rods. If such were the case, the course of rod as-

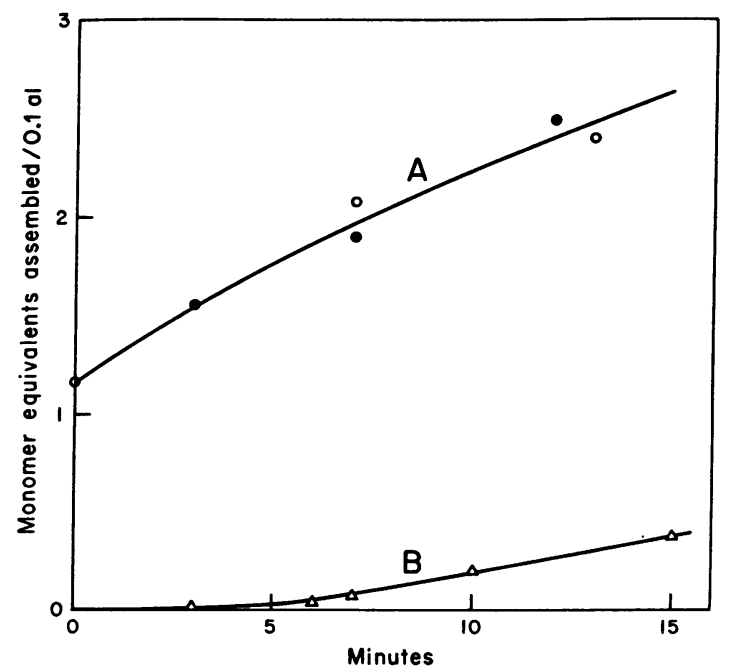

Fig. 2. Conversion of TMV protein to TMV rods. Curve A: disc protein was previously reacted with RNA for 3 min at $20^{\circ}$ and, $(O)$ reaction continued for the time shown, $(\bullet)$ reaction mixture was chilled to $0^{\circ}$ for $15 \mathrm{~min}$, warmed again to $20^{\circ}$, and reaction was then allowed to proceed for the time shown. Curve B: disc protein was previously chilled at $0^{\circ}$ for $15 \mathrm{~min}$ (to convert to A-protein), warmed again to $20^{\circ}$ and RNA was immediately added; reaction proceeded for the time shown. al, attoliter $=10^{-18}$ liter. Reactions were in sodium phosphate buffer.

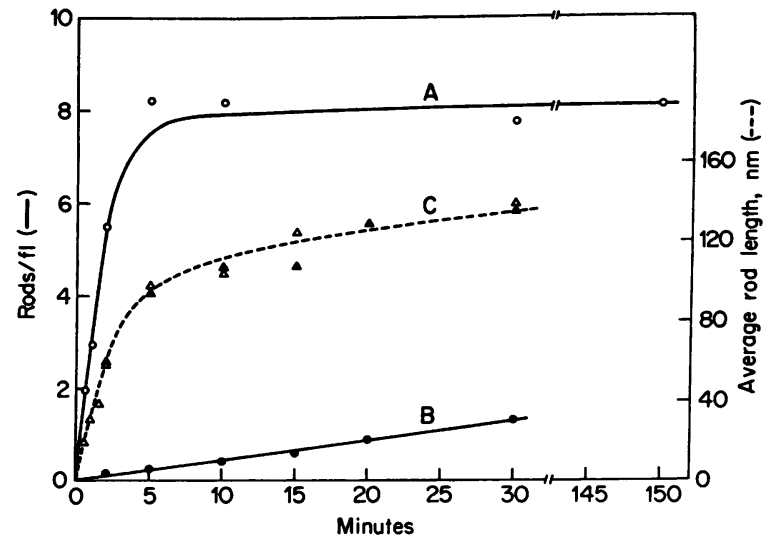

Fig. 3. TMV rod assembly: comparison of rod numbers and rod lengths. Reactions were in sodium pyrophosphate buffer. Curve A: disc protein; Curve B: A-protein; Curve $C:(\Delta)$ disc protein, and $(\mathbf{\Delta})$ A-protein.

sembly shown in Fig. 2, Curve A, could be explained qualitatively by the same mechanism: that when previously initiated rods were initially exposed to only A-protein, at $20^{\circ}$, their growth was due to sequential addition of the disc structures that were formed during the $15 \mathrm{~min}$ of the reaction. A comparison of $C$ urves $A$ and $B$ (Fig. 2), however, shows that at the end of $15 \mathrm{~min}$ only about $25 \%$ of the rod growth represented in Curve $A$ can be ascribed to the rod growth shown in $C$ urve $B$, without regard to assembly mechanism. We therefore conclude that the data in Fig. 2 are most reasonably interpreted to show TMV rod growth by incorporation of protein structures of the size of A-protein, or smaller.

\section{TMV rod formation in sodium pyrophosphate buffer}

Fig. 3 shows the progress of rod assembly under conditions similar to those used by Butler and Klug (1). As was found in sodium phosphate buffer (Fig. 1), the number of rods increases rapidly when disc protein is the protein added to the reaction mixture (Curve $A$ ), and much more slowly when Aprotein alone is added (Curve $B$ ). On the other hand, the lengths of the rods that are formed when A-protein alone is added (Curve $C, \mathbf{\Delta}$ ) are closely similar to the lengths when disc protein is added (Curve $C, \Delta$ ). This similarity in lengths, in fact, reveals that the A-protein alone causes a more rapid growth of rods than does the disc protein, since the average rod shown in Curve $C, \Delta$ at the end of, say, $20 \mathrm{~min}$ had been initiated only $10 \mathrm{~min}$ previously, while the average rod shown in Curve $C, \Delta$ had been in existence for about $17 \mathrm{~min}$. It is apparent that the effect of the initial presence of discs is a rapid and extensive initiation of rod formation. When A-protein alone is introduced into the reaction mixture, the initiation of rod formation proceeds much more slowly, but subsequently each initiated rod grows at a rate even greater than it does when only disc protein is present.

Our results are not easily explained by a TMV assembly mechanism that invokes the sequential addition of TMV protein discs to the growing structure. They are, however, consistent with a mechanism in which the nucleation of rod formation is the binding of a terminal stretch of RNA with a two-ring disc $(1,7)$, with elongation ensuing as a result of incorporation of distinctly smaller TMV protein aggregates. Since ultracentrifuge patterns show little material between disc size (20 S) and larger, and A-protein (4 S) and smaller, 
we conclude that the assembly structures are monomers or small-number oligomers. When disc protein is the material added to the RNA the first step is nucleation of rods, followed by incorporation of some of the A-protein aggregates present in the disc protein material. As the A-protein is progressively sequestered by permanent incorporation into rods, the equilibrium between discs and A-protein is perturbed in a manner such as to effect a net depolymerization of some of the remaining discs. Thus, the absolute concentration of the A-protein may remain fairly constant until the total protein supply is almost exhausted.

The proposed mechanism of TMV assembly is consistent with the turbidity data obtained (1), showing that a reaction mixture containing only A-protein as its protein component becomes turbid very slowly and that the addition of disc protein causes turbidity to rise rapidly. Turbidity measurements do not distinguish between numerous short rods and relatively few long rods. Thus, the low turbidity found when only A-protein is added to the reaction mixture does not preclude the existence of a low concentration of rods of relatively great length, as we have shown in Fig. 3. Addition of disc protein provides many nucleation centers, and rod growth by incorporation of low-number oligomers would result in the growth of many rods at a time, thus rapidly increasing the turbidity.

\section{Note on testing the assembly mechanism} by use of ${ }^{3} \mathrm{H}$-labeled TMV protein

If the assembly mechanism proposed here is correct, it might be expected that verification could be obtained by experiments with radioactively labeled TMV protein. Thus, an assembly mixture containing equal amounts of disc protein (of which $70 \%$ consists of discs and $30 \%$ of A-protein), labeled with ${ }^{3} \mathrm{H}$, and of unlabeled A-protein should produce sedimentable TMV rods whose specific activity would be $23 \%$ of that of the disc protein. Conversely, a mixture with equal amounts of unlabeled disc protein and labeled A-protein should yield rods with $77 \%$ of the specific activity of the A-protein. If the Butler and Klug assembly mechanism is correct, it might be expected that the former mixture would give rise to rods with $100 \%$ of the specific activity of the disc protein, while rods formed from the latter mixture should have negligible activity. Experiments to test the assembly mechanism by use of isotopically labeled protein have been performed in collaboration with Dr. H. Fraenkel-Conrat. In repeated tests the specific activity of the sedimentable rods was $50 \pm 5 \%$ of that of the labeled protein component. The tests were performed with both kinds of mixtures (labeled disc protein; labeled A-protein), with both phosphate and pyrophosphate buffers, and for reaction times of 3-180 $\min$.

The above results suggest that rapid interchange takes place between subunits within the discs and those outside. Two preliminary tests of this hypothesis were performed by mixing equal weights of labeled disc protein (containing about $30 \%$ A-protein) and unlabeled A-protein, and sedimenting the mixture for 30 and $75 \mathrm{~min}$ at $105,000 \times g$, without refrigeration. A visibly distinctive separation of discs from smaller protein units was achieved; material taken from just below the meniscus had a protein concentration of only $5 \%$ of that of the starting material. Samples were taken from the top of the tube and from the average contents after mixing. The specific activity of the material from the top portion was about $85 \%$ of that of the mixed material, instead of the $46 \%$ that would be expected if no interchange had taken place. It appears from these results that interchange of subunits into and out of the discs occurs. Hence, isotopic labeling appears inapplicable for investigation of the mechanism of in vitro assembly of TMV rods.

This work was supported by U.S. Public Health Service Research Grant CA 02245 from the National Cancer Institute and Postdoctoral Fellowship AI 50591 from the National Institute of Allergy and Infectious Diseases, and by National Science Foundation Research Grant GB 6918.

1. Butler, P. J. G. \& Klug, A. (1971) "Assembly of the particle of tobacco mosaic virus from RNA and disks of protein," Nature New Biol. 229, 47-50.

2. Durham, A. C. H. \& Klug, A. (1971) "Polymerization of tobacco mosaic virus protein and its control," Nature New Biol. 229, 42-46.

3. Durham, A. C. H., Finch, J. T. \& Klug, A. (1971) "States of aggregation of tobacco mosaic virus protein," Nature New Biol. 229, 37-42.

4. Backus, R. C. \& Williams, R. C. (1950)"The use of spraying methods and of volatile suspending media in the preparation of specimens for electron microscopy," J. Appl. Phys. 21, 11-15.

5. Fraenkel-Conrat, H., Singer, B. \& Tsugita, A. (1961) "Purification of viral RNA by means of bentonite," Virology 14, 54-58.

6. Durham, A. C. H. (1970) Thesis, University of Cambridge, Cambridge, England.

7. Okada, Y. \& Ohno, T. (1972) "Assembly mechanism of tobacco mosaic virus particle from its ribonucleic acid and protein," Mol. Gen. Genet. 114, 205-213. 